\title{
PENCUCIAN BAHAN ORGANIK TANAH PADA TIGA PENGGUNAAN LAHAN DI DAERAH HUTAN HUJAN TROPIS SUPER BASAH PINANG-PINANG GUNUNG GADUT PADANG
}

\author{
Yulnafatmawita, Adrinal, dan Arief $F$ auzan Hakim \\ Laboratorium Fisika Tanah F akultas Pertanian U niversitas Andalas Padang
}

\begin{abstract}
Study about soil organic matter (SOM) leaching in soil profiles of tropical rain forest was conducted in Bukit Pinang-Pinang, the upper footslope of Mt. Gadut in West Sumatra, and in Soil Physical laboratory Andalas University Padang. Bukit Pinang-Pinang is located on 480$640 \mathrm{~m}$ asl and geographically is between $100^{\circ} 29^{\prime} 40^{\prime \prime}$ and $100^{\circ} 30^{\prime} 20 \mathrm{E}$ ' as well as between $0^{\circ} 54^{\prime} 55^{\prime \prime}$ and $0^{\circ} 55^{\prime} 45^{\prime \prime} \mathrm{S}$. This rain forest area is known as a super wet area because it receives high annual rainfall $(>3500 \mathrm{~mm})$. The objective of this research was to measure the amount of SOM leached from top soil into the deeper soil. Undisturbed soil samples were taken from three different land uses, forest, bush, and mixed garden, on the top, middle, and foot slopes. Undisturbed soil samples were leached with distilled water as the amount of rainfall accepted in natural condition. The results showed that, land use change from forest into ecosystems of mixed garden (for over 50 years with $100 \%$ soil surface coverage and without any cultivation) and bush land (for over 20 years left) did not cause the SOM content in the profiles decreased. Amount of SOM leached from the top 0-10 cm was found greater from mixed garden, then followed by forest on the upper slope, forest on the middle slope, and bush area.
\end{abstract}

Keywords: SOM leaching, land use change, tropical rain forest, bush, mixed garden

\section{PENDAHULUAN}

Karbon organik (OC) yang ada dalam bahan organik (BO) telah lama dikenal sebagai salah satu penciri kesuburan tanah dan lahan produktif. Sebaliknya, tanah merupakan tempat pencadangan BO terbesar dalam ekosistem darat, dan berperan penting dalam siklus karbon (C) global. Tanah dan $\mathrm{BO}$ merupakan dua hal yang saling tergantung. Bahan organik butuh tanah untuk berlindung secara fisik dari proses oksidasi, sedangkan tanah butuh BO untuk kesuburan fisik, kimia, dan biologinya.

Dalam bidang fisika, BO dapat menurunkan bobot volume (BV) tanah, menyeimbangkan pori makro dan mikro, memperlancar aerase dan drainase, serta meningkatkan retensi dan transmisi air. Selanjutnya, BO dapat menyatukan butir tunggal dan merajut aggregate mikro menjadi makro, serta menstabilkan aggregat tanah. Tanah dengan aggregate yang stabil akan mampu melewatkan air hujan ke dalam tanah (infiltrasi) secara kontinuitas, menekan limpasan permukaan (runoff). Dengan demikian, fungsi hutan sebagai pengatur siklus hidrologi berjalan lancar, resiko bencana alam seperti banjir dan lonsor di musim hujan dan kekeringan di musim kemarau, dapat dihindari.

Akan tetapi, BO tanah bersifat dinamik. Kandungannya mudah berubah dari suatu tanah ke tanah yang lain, dari suatu tempat ke tempat lain, dari suatu ekosistem ke ekosistim yang lain, dan dari suatu kondisi iklim ke iklim lainnya. Hal ini bukan saja dipengaruhi oleh vegetasi yang tumbuh sebagai sumber BO nya, tetapi juga oleh kondisi tanah yang akan menyimpan BO tersebut, serta faktor yang bisa mempercepat proses kehilangannya. Oleh sebab itu, kandungan BO tanah tidak akan sama pada lokasi yang berbeda.

Di samping itu, kandungan BO tanah suatu lahan juga akan berbeda dengan waktu. Hal ini disebabkan karena BO merupakan sumber energi mikroba. Aktifitas mikroba merombak BO sangat tergantung kondisi lingkungan, terutama suhu dan kelembaban. Musim yang berbeda akan membedakan suhu dan kelembaban tanah, sehingga laju dekomposisi BO tidak 
akan sama, di samping laju pertumbuhan tanaman dan jumlah BO yang disumbangkannya ke tanah juga berbeda. Oleh sebab itu, jika tidak ada penambahan BO kepada suatu tanah, maka BO nya akan menurun dengan waktu.

Kehilangan BO dari tanah bisa secara horizontal di permukaan tanah serta secara vertikal kebawah dalam profil tanah. Kehilangan vertikal keatas dalam bentuk gas $\mathrm{CO} 2$ terjadi setelah proses dekomposisi BO. Kehilangan BO secara vertikal ke bawah dapat tercuci dari permukaan ke dalam atau ke bawah profile tanah melalui proses infiltrasi dan perkolasi. Kehilangan secara vertikal ke dalam profil tanah bisa meningkatkan cadangan bahan organik di daratan, selama BO tersebut tidak keluar dari profil tanah. Hal ini akan bernilai positif terhadap peningkatan kemampuan tanah dalam menahan air.

Bagian hulu suatu daerah aliran sungai merupakan regulator hidrologi bagi daerah alirannya. Daerah tersebut harus mampu menyerap air hujan yang jatuh dan menyimpannya dalam tanah, agar tercipta lingkungan aman yang lestari. Alih fungsi lahan yang marak beberapa dekade terakhir telah merusak fungsi hutan sebagai pengatur siklus air. Widianto et al (2005) mendapatkan bahwa pengubahan hutan menjadi lahan tanaman kopi monokultur setelah 10 tahun belum mampu mengembalikan fungsi hutan tersebut walaupun penutupan kanopi sudah mencapai $100 \%$. Oleh sebab itu, daerah ini harus dikonservasi agar kelestarian lingkungan dapat dipertahankan.

Pinang-Pinang merupakan suatu bukit yang terletak di kaki gunung Gadut, kawasan hutan hujan tropis dengan curah hujan tahunan mencapai $\pm 6500 \mathrm{~mm}$, tanpa musim kering yang nyata (Rasyidin, 1994). Berdasarkan peta JANTOP TNI, daerah kawasan g.Gadut ini merupakan hulu dari beberapa sungai, dua diantaranya melintasi kota Padang, yaitu sungai Batang Arau dan Batang Kuranji. Daerah Bukit PinangPinang yang berada pada kaki g.Gadut bagian atas ini berada pada ketinggian 390$640 \mathrm{~m}$ dpl. Daerah ini dilalui 2 sungai yaitu Bt.Lantiak dan Sungai Gadut Gadang yang merupakan hulu dari sungai Batang Kuranji yang melintasi kota Padang. Oleh sebab itu, daerah hutan disini harus dilestarikan agar daerah alirannya, khususnya kota Padang, tidak mengalami bencana alam seperti yang dialami banyak daerah lain di Indonesia.

Akan tetapi, daerah kawasan bukit Pinang-Pinang ini sudah dibuka semenjak beberapa dekade belakangan. Pembukaan hutan berarti perubahan sumber dan laju dekomposisi BO tanah. Bahan organik merupakan salah satu indikator kesehatan fisik tanah. Tanah yang kekurangan BO mempunyai kepekaan yang tinggi terhadap degradasi lahan dan erosi, terutama di daerah berlereng curam dan ber $\mathrm{CH}$ tinggi, seperti di daerah Sumatra Barat. Dalam kondisi ekstrim, Irianto (2004) menjelaskan bahwa alih fungsi lahan berdampak terhadap pengurasan cadangan air tanah, penurunan produksi air DAS, meningkatkan konsumsi air tanaman melalui transpirasi, dan yang paling menakutkan adalah banjir.

Bertitik tolak dari kenyataan diatas, dilakukan penelitian tentang pergerakan BO tanah daerah Pinang-Pinang dalam profil tanah, dari tanah lapisan atas ke lapisan bawah.

\section{BAHAN DAN METODA}

Penelitian ini dilakukan di PinangPinang, kaki gunung Gadut bagian atas dengan menggunakan metoda survai. Sampel diambil pada 3 kelerengan: lereng atas (puncak), lereng tengah (pinggang), serta lereng bawah (kaki), dan pada 3 penggunaan lahan: hutan, semak belukar, serta kebun campuran. Sampel tanah utuh dengan menggunakan paralon setebal $30 \mathrm{~cm}$ dari permukaan tanah diambil pada masingmasing penggunaan lahan yang ada di lereng puncak, tengah, dan bawah. Analisis Corganik (metoda Walkley and Black) dilakukan di Laboratorium Kimia Tanah. Analisis tekstur dan pencucian BO dilakukan di laboratorium Fisika Tanah serta Faperta Unand Padang. Tanah dalam paralon ditetesi air dengan kecepatan dan jumlah tetes yang berbeda sampai $3000 \mathrm{~mm}$ (sama dengan jumlah $\mathrm{CH}$ daerah PinangPinang selama 6 bulan) air terpakai.

HASIL DAN PEMBAHASAN 
Kondisi Daerah Penelitian

Dari hasil survai dan wawancara dengan masyarakat sekitar dilapangan maka diperoleh informasi bahwa telah terjadi penebangan di Bukit Pinang Pinang ini semenjak beberapa dekade yang lalu. Akibat penebangan tersebut terdapat tiga penggunaan lahan di daerah ini, yaitu hutan, kebun campuran dan semak belukar.

Hutan

Lahan hutan terdapat dipinggang dan puncak bukit (antara 570-640 m dpl). Kawasan hutan Pinang Pinang ini mempunyai keragaman hayati yang sangat tinggi. Berdasarkan hasil penelitian Masunaga et al (1997) terdapat sekitar 472 spesies pohon pada puncak bukit PinangPinang yang hanya berukuran \pm 1 ha. Tanah di daerah hutan ini mempunyai solum yang dangkal dan kedalaman efektif $<30 \mathrm{~cm}$. Bahkan pada sebagian lubang pemboran, batu sudah ditemukan pada lapisan $20 \mathrm{~cm}$.

Menurut Wakatsuki (1986) ordo tanah di daerah bukit Pinang-Pinang ini termasuk Inceptisols dengan tiga subgroup, yaitu Typic Dystropept, Lithic Dystropept, dan Lithic Eutropept. Jadi daerah ini memang tidak layak dibuka untuk lahan pertanian, karena bisa mengakibatkan kehilangan lapisan tanahnya serta menimbulkan lahan kritis dan bencana alam.

\section{Semak Belukar}

Lahan semak berasal dari bekas penebangan hutan yang telah lama $(>20$ tahun) ditinggalkan, terdapat pada pinggang bukit (590-600 m dpl), dengan luas 21,23 ha Tumbuhan yang tumbuh pada lahan semak ini diantaranya krinyuh (Chromolaena odorata), jelatang, sikaduduak (M elastoma malabtaricum), paku resam (Gleicenia linearis), linju, pandan (Pandanus, sp), rimbang (Solanum Sp) dan tanaman semak lainnya. Tidak berbeda dengan penggunaan lahan hutan dan kebun campuran, tanah pada semak ini juga mempunyai kedalaman efektif yang dangkal, $<30 \mathrm{~cm}$. Akan tetapi, sebagian lokasi masih bisa dibor sampai ke dalaman $100 \mathrm{~cm}$ walaupun sudah terdapat bahan induk pada kedalaman $40 \mathrm{~cm}$.

Kebun Campuran
Kebun campuran merupakan lahan hutan yang sudah ditebang ( $>50$ tahun) dan ditanami oleh masyarakat dengan tanaman tahunan untuk menambah pendapatan mereka. Pada umumnya kebun ini terdapat pada ketinggian 480-488 $\mathrm{m}$ dpl atau pada kaki bukit dengan luas sekitar 14.05 ha.

Tanaman utama pada lahan ini yaitu manggis (Garcinia mangostana, L), durian (Durio zibetinus), kayu manis (Cinnamum burmanii) dan coklat (Theobroma cacaco, L). Disamping tanaman tua, juga terdapat tanaman pisang (M usa, sp) yang bisa dipanen petani dalam waktu pendek dan tidak tergantung musim. Selain tanaman komersial diatas, tanah pada lahan ini juga ditumbuhi oleh tanaman bawah (understorey) yang permanen dan alami, diantaranya yang dominan anggrek tanah, linju, dan rumput-rumputan (G raminae sp).

Seperti lahan hutan, tanah dikaki bukit atau di bawah kebun campuran ini juga mempunyai solum yang dangkal, bahkan batuan besar banyak terdapat di permukaan tanah. Dari hasil pemboran dan pengambilan sample terganggu dan utuh, kedalaman efektif tanah $<30 \mathrm{~cm}$. Akan tetapi, warna tanah disini lebih gelap dibanding warna tanah di semak belukar dan di hutan.

\section{Tekstur Tanah}

Kelas tekstur tanah secara umum pada lapisan atas $(0-20 \mathrm{~cm})$ lebih kasar (Liatlempung), sedangkan pada lapisan bawah pada umumnya liat, kecuali kebun campuran. Tekstur tanah yang lebih kasar pada bagian kaki bukit disebabkan karena tanah tersebut kemungkinan masih baru mengalami deposisi. Hal ini bukan saja dicirikan oleh solum yang dangkal, tetapi juga dengan banyaknya ditemukan batuan pada solum tanah, bahkan mencapai kedalaman 10-20 $\mathrm{cm}$. Kondisi demikian menyebabkan tanah menjadi poros, mempunyai pori makro yang cukup tinggi.

\section{Kandungan Bahan Organik Tanah}

Secara umum kandungan BO tanah menurun dengan kedalaman (Tabel 2) pada setiap penggunaan lahan. Tingginya kandungan BO pada tanah kandungan BO pada tanah utama $\mathrm{BO}$ berasal dari bahan 
organik yang jatuh kepermukaan tanah, seperti daun, ranting, dan batang tanaman yang melapuk. Walaupun sumber BO juga bisa berasal dari akar tanaman yang membusuk atau eksudat akar tanaman yang masih hidup, prosentasenya jauh lebih kecil dibanding bagian tanaman yang menumpuk di permukaan tanah lapisan atas disebabkan karena sumber utama BO berasal dari bahan organik yang jatuh kepermukaan tanah, seperti daun, ranting, dan batang tanaman yang melapuk. Walaupun sumber BO juga bisa berasal dari akar tanaman yang membusuk atau eksudat akar tanaman yang masih hidup, prosentasenya jauh lebih kecil dibanding bagian tanaman yang menumpuk di permukaan tanah.

Tabel 1. Tekstur tanah daerah Bukit Pinang-Pinang pada tiga kelerengan dan tiga penggunaan lahan

\begin{tabular}{lll}
\hline Lereng & Penggunaan Lahan & Tekstur \\
\hline$\underline{0-20 \mathrm{~cm}}$ & & \\
Puncak & Hutan & Lempung Liat Berdebu \\
Pinggang & Hutan & Liat - Lempung Liat Berdebu \\
& Semak Belukar & Liat - Liat Berdebu \\
Kaki & Kebun Campuran & Lempung - Lempung berdebu \\
$\underline{20-40 \mathrm{~cm}}$ & & \\
Puncak & Hutan & Liat \\
Pinggang & Hutan & Liat - Lempung Liat Berdebu \\
Kaki & Semak Belukar & Liat \\
& Kebun Campuran & Lempung berdebu \\
\hline
\end{tabular}

Seiring dengan semakin rendahnya kandungan BO dengan kedalaman, aktifitas mikroba tanah juga menurun. Mikroba yang berperan sebagai penyumbang $\mathrm{BO}$ juga sangat tergantung pada kandungan $\mathrm{BO}$ tanah, karena BO merupakan sumber energi bagi mikroba. Oleh sebab itu, kandungan BO tanah semakin berkurang dengan semakin jauhnya dari permukaan tanah.

Penurunan kandungan $\mathrm{BO}$ tanah denga kedalaman profil di kawasan Pinang-Pinang ini sesuai dengan yang didapatkan beberapa peneliti sebelumnya. Yulnafatmawita et al (2007) di Bukit Gajabuih kawasan G.Gadut Padang dan Yulnafatmawita et al (2006) di hulu DAS Sumpur menemukan hal yang sama. Cramp (2001) juga mendapatkan penurunan kandungan C-organik tanah dengan kedalaman profil pada tanah Ferrosol hutan hujan (rain forest) negara bagian Queensland Australia. Penurunan kandungan BO profil tanah Pinang-Pinang ini mengikuti pola yang sama untuk setiap satuan lahan, yaitu penurunan berkurang (Gambar 1).
Adanya kecendrungan peningkatan kandungan BO tanah pada lahan kebun campuran bukan disebabkan oleh terjadinya pemindahan BO tanah secara horizontal dari puncak ke pinggang ataupun kaki bukit. Akan tetapi, hal tersebut dapat disebabkan oleh beberapa hal, diantaranya oleh derajad kelerengan yang kecil $\left(8^{\circ}\right)$ dan $\mathrm{BO}$ segarnya berasal dari dua sumber yaitu serasah dan tanaman bawah.

Kemudian, tekstur tanah yang relatif lebih kasar (Lempung-lempung berdebu) mengakibatkan laju infiltrasi tanah yang tinggi, sehingga runoff dapat diminimalisir. Di samping itu, permukaan tanah yang ditumbuhi oleh tanaman bawah secara permanen dan alami juga telah membatasi terjadinya runoff. Oleh sebab itu, dapat disimpulkan bahwa kehilangan BO melalui aliran runoff dapat dikatakan nihil, dan semua BO segar yang berasal dari serasah dan cover crop bisa menjadi BO tanah. Selanjutnya, tanaman bawah yang menutupi permukaan tanah pada kebun campuran biasanya dibabat oleh petani yang empunya 
kebun secara reguler, minimal saat musim buah tiba. Dengan demikian proses penimbunan dan dekomposisi BO menjadi lebih cepat dibanding di bawah hutan. Jadi dapat disimpulkan, bahwa kandungan $\mathrm{BO}$ tanah pada lahan hutan yang sudah beralih fungsi menjadi kebun campuran dapat menyamai kandungan $\mathrm{BO}$ tanah hutan, jika permukaan tanahnya ditutupi $100 \%$ oleh tanaman penutup tanah atau semak setelah lebih dari 50 tahun dan tidak pernah diolah.

Tabel 2. Distribusi BO Profil Tanah Pinang-Pinang Pada Puncak, Pinggang, dan Kaki Bukit

\begin{tabular}{|c|c|c|c|c|c|}
\hline \multirow[t]{2}{*}{ Lereng } & \multirow{2}{*}{$\begin{array}{l}\text { Penggunaan } \\
\text { Lahan }\end{array}$} & \multirow{2}{*}{$\begin{array}{l}\text { Kedalaman } \\
\mathrm{cm}\end{array}$} & \multicolumn{3}{|c|}{ BO-total } \\
\hline & & & $\%$-Vol & Std & Kriteria*) $^{*}$ \\
\hline \multirow[t]{3}{*}{ Puncak } & Hutan & $0-10$ & 5,12 & $(1,83)$ & $\mathrm{S}$ \\
\hline & & $10-20$ & 3,03 & $(1,25)$ & $\mathrm{R}$ \\
\hline & & $20-30$ & 2,43 & $(1,18)$ & $\mathrm{R}$ \\
\hline \multirow[t]{6}{*}{ Pinggang } & Hutan & $0-10$ & 5.60 & $(0,37)$ & $S$ \\
\hline & & $10-20$ & 3.87 & $(0,13)$ & S \\
\hline & & $20-30$ & 2.57 & $(0,21)$ & S \\
\hline & Semak & $0-10$ & 5.20 & $(2,11)$ & S \\
\hline & Belukar & $10-20$ & 3,66 & $(0,87)$ & S \\
\hline & & $20-30$ & 2,26 & $(0,50)$ & $\mathrm{R}$ \\
\hline \multirow[t]{3}{*}{ Kaki } & Kebun & $0-10$ & 10.30 & $(0,60)$ & $\mathrm{T}$ \\
\hline & Campuran & $10-20$ & 4.40 & $(0,79)$ & S \\
\hline & & $20-30$ & 3,14 & $(0,38)$ & $\mathrm{R}$ \\
\hline
\end{tabular}

\section{Kehilangan Bahan Organik Tanah}

Kehilangan BO tanah vertikal ke bawah (dalam profil tanah) disajikan pada Tabel 3. Perpindahan BO dari permukaan tanah ke lapisan lebih dalam tidak dianggap kehilangan selama BO tidak keluar dari profil tanah. Bahkan perpindahan tersebut menguntungkan karena bisa meningkatkan cadangan carbon organik (CO) daratan. Dari hasil percobaan laboratorium, penambahan air kepermukaan kolum tanah utuh memindahkan BO lapisan atas (0-10 $\mathrm{cm})$ ke lapisan di bawahnya pada setiap profil tanah. Prosentase perpindahan BO tertinggi ditemukan pada profil tanah kebun campuran $\left(1.1 \%=543.6 \mathrm{~g} \mathrm{OC} \mathrm{m}^{-2}\right)$, lalu diikuti oleh hutan puncak $(0.49 \%=273.5 \mathrm{~g}$ OC $\left.\mathrm{m}^{-2}\right)$, hutan di pinggang $(0.37 \%=182.8$ g OC $\left.\mathrm{m}^{-2}\right)$ dan semak belukar $(0.31 \%=$ $173.0 \mathrm{~g} \mathrm{OC} \mathrm{m}^{-2}$ ).

Perpindahan BO pada profil tanah dipengaruhi oleh tekstur tanah. Semakin kasar tekstur, semakin banyak jumlah pori makro, semakin poros tanah, dan semakin tinggi laju infiltrasi yang berpeluang menghanyutkan $\mathrm{BO}$ ke dalam profil tanah. Tekstur tanah (Tabel 1) pada kebun campuran yang relatif lebih kasar (lempung) dari yang lain mempunyai pori makro yang cukup tinggi untuk meloloskan BO yang lebih banyak. Sebaliknya, semak belukar dan hutan di pinggang bukit dengan tekstur yang lebih halus (liat-lempung liat berdebu) meloloskan BO lebih sedikit.

Kehilangan BO secara horizontal di permukaan tanah dengan aliran air permukaan di kawasan Bukit Pinang-Pinang in belum ada. Hal ini disebabkan oleh 
beberapa hal, diantaranya karena permeabilitas tanah tegolong cepat, sehingga jumlah air yang hujan yang jatuh lansung diserap oleh tanah. Bahan organik tanah yang termasuk sedang dipermukaan $0-10 \mathrm{~cm}$ dapat meransang agregasi dan memantapkan aggregatnya serta menyeimbangkan pori makro dan mikro, sehingga laju infiltrasi tanah lebih besar dari laju $\mathrm{CH}$.

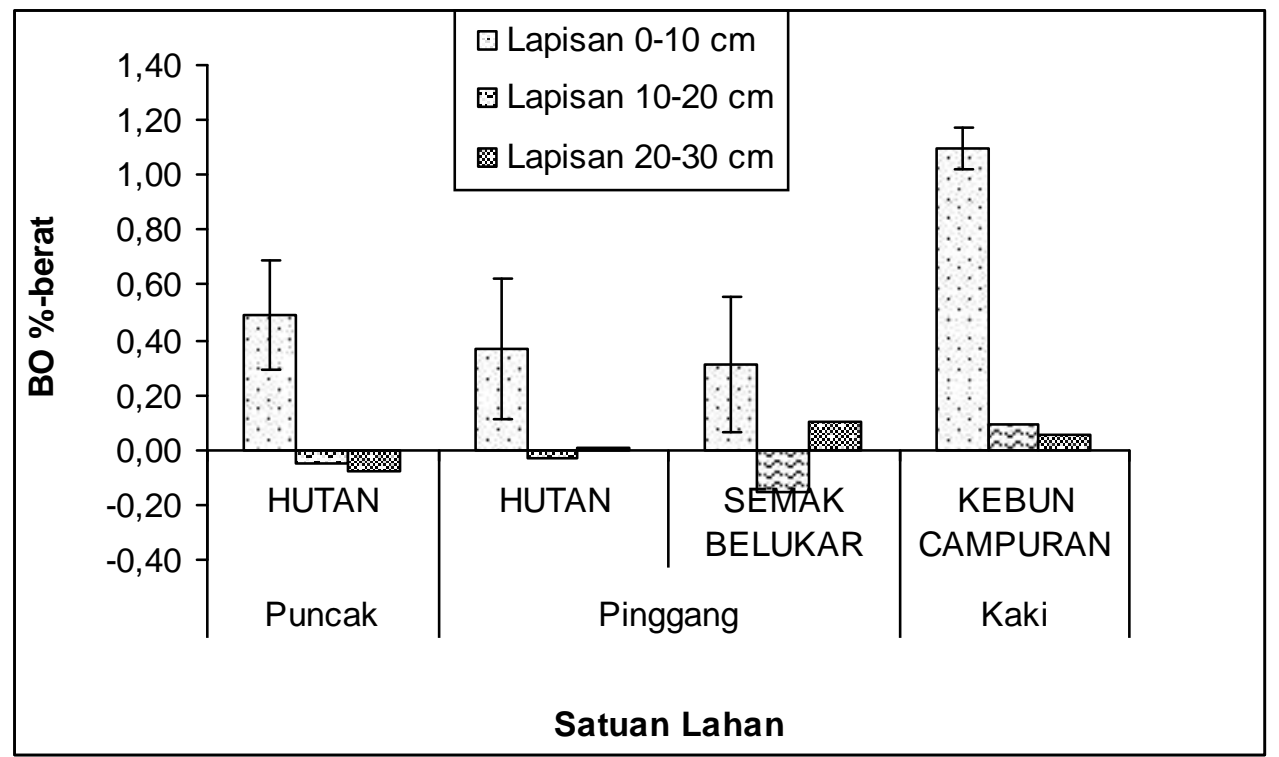

Gambar 1. Jumlah BO yang tercuci dari profil tanah Pinang-Pinang kawasan Hutan Hujan Tropik super basah G.Gadut Padang

Tabel 3. Kehilangan BO tanah Bukit Pinang-Pinang

$\begin{array}{lll}\text { LERENG } & \text { PENGGUNAAN LAHAN tercuci (\%) }\end{array}$

\section{LAPISAN 0-10 CM}

$\begin{array}{lll}\text { Puncak } & \text { Hutan } & 0,49(0.39)^{*} \\ \text { Pinggang } & \text { Hutan } & 0,37(0.51) \\ & \text { Semak Belukar } & 0,31(0.49) \\ \text { Kaki } & \text { Kebun Campuran } & 1,10(0,15)\end{array}$

\section{LAPISAN 10-20 CM}

\begin{tabular}{llr}
\hline Puncak & Hutan & $-0,05(0,21)$ \\
Pinggang & Hutan & $-0,03(0,27)$ \\
& Semak Belukar & $-0,15(0,86)$ \\
Kaki & Kebun Campuran & $0,09(0,63)$
\end{tabular}

\section{LAPISAN 20-30 CM}

\begin{tabular}{llr} 
Puncak & Hutan & $-0,08(0,31)$ \\
Pinggang & Hutan & $0,02(0,52)$ \\
& Semak Belukar & $0,10(0,33)$ \\
Kaki & Kebun Campuran & $0,05(0,43)$ \\
\hline
\end{tabular}

Keterangan: *) Standar D eviasi 
Di samping itu, kanopi serta tanaman bawah juga berfungsi menurunkan atau menghambat terjadinya limpasan permukaan (runoff) dan meningkatkan laju infiltrasi. Widianto et al. (2005) mendapatkan peningkatan laju infiltrasi pada penanaman kopi monokultur berumur 10 tahun dengan penutupan kanopi sudah mencapai $100 \%$. Hutan yang ditutupi oleh kanopi yang rapat, semak yang ditumbuhi oleh tanaman yang rimbun, dan kebun campuran yang ditumbuhi oleh tanaman tua dan tanaman bawah alami yang tebal dapat menekan runoff dan erosi serta meningkatkan kapasitas infiltrasi pada kawasan Pinang-Pinang ini.

\section{KESIMPULAN DAN SARAN}

\section{Kesimpulan}

Dari hasil penelitian yang dilakukan, baik hasil pengamatan di lapangan maupun hasil analisis di laboratorium, maka dapat disimpulkan bahwa pada daerah Bukit Pinang-Pinang:

1. Alih fungsi lahan dari hutan menjadi semak belukar (setelah $>20$ tahun dibiarkan) dan kebun campuran (setelah > 50 tahun ditanami tanaman tua dan ditumbuhi tanaman bawah "understorey" secara permanen) tidak menurunkan (sama pada kriteria sedang), bahkan cendrung meningkatkan kadar BO tanah. Kadar BO tanah permukaan $(0-10 \mathrm{~cm})$ yaitu $5.88 \%$, $8.59 \%, 8.75 \%$, dan $9.71 \%$ untuk hutan di puncak bukit, hutan di pinggang bukit, semak belukar, dan kebun campuran, secara berturut-turut.

2. Terjadi kehilangan $\mathrm{BO}$ tanah vertikal ke bawah sebanyak 273.5, 182.8, 173.0, dan $543.6 \mathrm{~g} \mathrm{OC} \mathrm{m}^{-2}$ (6 bulan $)^{-1}$, pada lapisan 0 $10 \mathrm{~cm}$ untuk hutan di puncak bukit, hutan di pinggang bukit, semak belukar, dan kebun campuran, secara berturut-turut.

Saran

Berdasarkan hasil penelitian yang diperoleh, maka disarankan untuk tidak membuka hutan agar fungsinya sebagai pengatur hidrologi bisa dipertahankan. Akan tetapi, jika suatu area di daerah hutan hujan tropik super basah ini harus dibuka, hanya dibolehkan lahan berkelerengan $<10^{\circ}$. Setelah itu lahannya harus ditanami dengan tanaman tua yang permukaan tanahnya $100 \%$ ditutupi oleh tanaman bawah secara permanen. Hal ini bertujuan untuk mempertahankan BO tanah, meningkatkan laju infiltrasi, meniadakan aliran permukaan, atau mengembalikan fungsi hidrologis hutan dalam rangka mengantisipasi bencana alam di daerah aliran sungainya. Mengingat kandungan BO tanah hanyalah salah satu faktor penentu terhadap degradasi lahan, maka penelitian lanjutan dari aspek lain sangat disarankan.

A knowledgement: Pada kesempatan ini penulis mengucapkan terima kasih kepada DP2M Ditjen DIKTI yang telah membiayai proyek penelitian Fundamental ini untuk tahun 2007.

\section{DAFTAR PUSTAKA}

Aflizar. 2003. Hubungan serasah dan karakteristik fisika dan unsur hara dalam tanah hutan hujan tropic super basah di Pinang-Pinang. Thesis Pasca Sarjana Univ. Andalas Padang, 146 hal.

Australian Greenhouse Office (AGO). 2002. National Greenhouse Gas Inventory 2000 with Methodology Supplements. Australian Greenhouse Office, Annual Report.

Cheng, W. and Coleman, D.C. 1989. A Simple method for measuring $\mathrm{CO} 2$ in a continuous air-flow system: modifications to the substrate-induced respiration technique. Soil Biol. Biochem, Vol. 21(3): 385-388

Hotta, M. 1984. Diversity and dynamic of plant life Sumatra. Part 2. Sumatra Nature Study (Botany). Kyoto Univ. Kyoto, 128 pp.

Irianto, G. 2004. Alih fungsi lahan: Dampaknya terhadap produksi air DAS dan banjir. Tabloid Sinar Tani. 
Irianto, G. 2005. Menyoal alih fungsi lahan, kekeringan, dan ketahanan pangan.

Kubota, D., Masunaga, T., dan Hermansah. 2000. Soil quality characterization in relation to tree spesies diversity in tropical rain forest, West Sumatra, Indonesia I. Comparison of two 1-ha plots. Tropics Vol. 9(2) 133-145.

Kubota, D., Masunaga, T., Hermansah, Rasyidin, A, Hotta, M., Shinmura, Y., and Wakatsuki, T. 1998. Soil environment and tree spesies diversity in tropical rainforest, West Sumatra Indonesia. In "Soils of Tropical Forest Systems: Characteristics, Ecology, and Management" edited by A. Schulte and Ruhiyat. Springer, Berlin, 159-167.

Kuc, T, Gorczyca, Z., and Kapusta, M. 2004. Carbon dynamics in soil recorded by ${ }^{14} \mathrm{C}$ : Model calculations. Geochronometria Vol 23:45-50.

Masunaga, T., Kubota, D., Hotta, M., and Wakatsuki, T. 1997. Mineral composistion of leaves and barks. In Aluminum Accumulator in Tropical Rainforest in Indonesia. Soil Sci. Plant Nutr., 44(3): 315-329.

Ogiono, K.,.Hotta, M., Tamin, R. dan Yoneda, T. 1984. Forest ecology of gunung Gadut Area. Sumatra Nature Study (Botany, Kyoto.

Pulleman, M.M., Bouma, J., van Essen, E.A., and Meijles, E.W. 2000. Soil organic matter content as a function of different land use history. Soil Sci. Soc. Am. J . 64:689-693

Rasyidin, A 1994. The method for measuring rates of weathering and rates of soil formation in watershed. Disertase. Tottory Univ. Japan, 110 p.

Supyayogo, D., Widianto, Purnomosidhi, P., Widodo, R.H.,Rusiana, F., Aini, Z.Z., Khasanah, N., dan Kusuma, Z. 2004. Degradasi sifat fisik tanah sebagai akibat alih guna lahan hutan menjadi system kopi monokultur: kajian perubahan makroporositas tanah. Agrivita 26(1):60-68
Widianto, Suprayogo, D., Noveras, H., Widodo, R.H., Purnomosidhi, P., dan van Noordwijk, M. 2005? Alih guna lahan hutan menjadi lahan pertanian: apakah fungsi hidrologis hutan dapat digantikan system kopi mono kultur? ICRAF SE Asia, PO Box 161, Bogor 16001

Voorhees, W.B. 2001. The $5^{\text {th }}$ conference of the international soil tillage research organization. Soil \& Tillage Research., $61,1-2$.

Wakatsuki, T., Saidi, A. and Rasyidin, A. 1986. Soil in topsequence of the gunung Gadut tropical rainforest, West Sumatra. South E ast Asian Studies 24(3):243-262

Yulnafatmawita, So, H.B., Dalal, R.C. and Menzies, N.W. 2003a. $\mathrm{CO}_{2}$ emission from different soil fraction following physical disruption: Implication for tillage practices. Proc. on the $16^{\text {th }}$ Triennial Int'l Soil Tillage Res.O rg.(ISTRO) Conference 13-18 J uly 2003, Brisbane Australia

Yulnafatmawita, So, H.B., Dalal, R.C. and Menzies, N.W. 2003b. $\mathrm{CO}_{2}$ emission from two contrasting soils under controlled (glasshouse) condition. Proc. The $16^{\text {th }}$ Triennial Int'I Soil Tillage Res. Org. (ISTRO) Conference, 13-18 July 2003, Brisbane Australia

Yulnafatmawita. 2004c. Effects of land use change on soil organic matter status of bulk and fractionated soil aggregates. Stigma Sci.J . Vol XII(2): 417:421

Yulnafatmawita. 2005. Fractionation of soils based on bonding energy and aggregate size: A method for studying the effect of structural hierarchy on degradation process. Disertase. Univ. of Queensland Brisbane, Australia, 209 pages.

Yulnafatmawita. 2006. Hubungan antara status C-organik dan stabilitas aggregat tanah Ultisol Limau Manis Padang akibat perubahan penggunaan lahan. Proc. Seminar Tahunan BKS 25-28 April $2006 \mathrm{~J}$ ambi. 
Yulnafatmawita, Utry Luki, Afri Yana. 2007. Kajian sifat fisika tanah beberapa penggunaan lahan di bukit Gajabuih dan sekitarnya, kawasan hutan hujan tropik
Gunung Gadut Padang Proc. Seminar Tahunan BKS 22-25 Juli 2007 Pekan Baru 